\title{
ViolenCiA Y RESISTENCIA ENTRE TSOTSILES DE SAN GREgorio y LAdinos de SAN ANdRÉS EN Huixtán, Chiapas. LA NARRATIVA DE UN TSOTSIL
}

\author{
Jaime Tomás Page Pliego* \\ Andrés Huacash Vázquez** \\ DOI: https://doi.org/10.31644/ED.V8.N1.2021.D01
}

\section{Introducción}

A los autores nos ha resultado complicado lograr el acceso a las historias y dinámicas socioculturales que tienen lugar en el área de San Gregorio. Aducimos que las razones que la población tiene para rechazar a la "gente de fuera" - y que ha llegado a constituirse en acuerdo de asamblea para no permitir su asentamiento, investigar, circular por el campo fuera de los caminos y mucho menos acceder a lo que aún se consideran lugares sagrados - se fincan en abusos de toda clase perpetrados por los kaxlantik, ${ }^{1}$ hechos que aún lastiman su memoria.

Como excepción y derivado de experiencias de colaboración y solidaridad, algunos de los pobladores no aceptan taxativamente dichos acuerdos, por lo que, por supuesto con ciertas reservas, al menos apoyan el trabajo de investigación, siempre que ello redunde en beneficio de su particular proyecto de vida o político. Así, la posibilidad de elaborar este documento y otros deriva de los lazos estrechos que se establecieron como resultado de un curso en salud impartido en la clínica autogestiva de Zitim, el cual concluyó en sólida amistad y confianza con algunos de sus miembros.

El documento tiene como propósito dar a conocer aquellos eventos que marcaron el fin de una época de opresión, explotación y maltrato, así como la reconfiguración de lo social desde lo religioso como vía para la reconstrucción de la dignidad; ello en el marco de la investigación "Representaciones sobre la visión del mundo en Zitim, Huixtán y Nuevo Tepeyac, Villa de Las Rosas, Chiapas", llevada a cabo en 2008 y encaminada a recabar narrativas que muestren las formas en que los mayas y ladinos de dichas comunidades conciben y viven el mundo.

* Dr. en Antropología, Investigador del Centro de Investigaciones Multidisciplinarias sobre Chiapas y la Frontera Sur, Universidad Nacional Autónoma de México. ORCiD: http://orcid.org/0000-0003-0508-0647 Correo-e: jaimepagepliego@gmail.com.

** Promotor de salud en Zitim, Huixtán, Chiapas, México. Correo-e: andresviento@gmail.com.

${ }^{1}$ Alejos (1994: 97) señala que “kaxlan, [es] 'el otro', categoría igualmente genérica con que nombran a todo aquel que no es como ellos. En su origen esta última fue una palabra derivada de castellano que nombraba al hombre blanco, al extranjero, y que se extendió por un amplio territorio, de manera que en la actualidad el término kaxlan se emplea en numerosas lenguas mayenses". Asimismo, el término tik implica pluralización.

Fecha de recepción: 19/05/2020. Fecha de aceptación: 16/07/2020. Fecha de publicación: 30/01/2021.

\section{(cc) BY-NC-ND}

EntreDiversidades. Revista de Ciencias Sociales y Humanidades, vol. 8, núm. 1 (16), enero-junio 2021. Páginas: 258 - 276 ISSN-e: 2007-7610. https://doi.org/10.31644/ED.V8.N1.2021.D01 
El acercamiento teórico lo realizamos a partir del análisis del discurso desde la perspectiva de Bajtín, interpretado por Alejos (1994):

Bajtín [...] señala que lo expresado verbalmente son siempre enunciados cuyo sentido involucra a lo social, es decir, que lo dicho lingüísticamente está en relación con un universo de relaciones sociales en curso, "porque el lenguaje participa de la vida a través de los enunciados concretos que lo realizan, así como la vida participa del lenguaje a través de los enunciados” (Bajtín, 1982: 251, citado en Alejos, 1994: 28).

Ante el planteamiento de presentar su testimonio bajo un alias, don Andrés Huacash Huet insistió en que su nombre debe aparecer al hacer referencia a sus narrativas. Cabe resaltar que lo elegimos como personaje principal de este documento por haber sido gestor y protagonista de los diferentes eventos mencionados.

\section{Contexto}

Las localidades de San Gregorio Las Casas, Zitim y San Andrés Puerto Rico se encuentran al oriente en el municipio de Huixtán de las Flores, Chiapas, a su vez localizado al oriente de la ciudad de San Cristóbal de Las Casas. La cabecera municipal se sitúa a la altura del kilómetro 30 de la carretera que va de San Cristóbal a Palenque. Para llegar a las localidades señaladas, en dirección a Palenque se toma un desvío a la derecha situado aproximadamente a tres kilómetros de la cabecera de Huixtán, por el que se transitan poco menos de $12 \mathrm{~km}$.

La carretera que llega a San Gregorio fue primero construida “a pico y pala” entre 1976 y 1978 por los habitantes de esta localidad y los de San Andrés, en principio de terracería y nuevamente trazada y pavimentada entre 2005 y 2006. Esta carretera transita bordeando escarpados cerros con bosques de coníferas en las laderas, y pastizales y milpas en las planadas, lo que resulta en un paisaje esplendoroso de clima templado húmedo con altitudes que oscilan entre los $2100 \mathrm{y}$ $2500 \mathrm{msnm}$.

EntreDiversidades. Revista de Ciencias Sociales y Humanidades, vol. 8, núm. 1 (16), enero-junio 2021. Páginas: 258 - 276 ISSN-e: 2007-7610. https://doi.org/10.31644/ED.V8.N1.2021.D01 
Mapa 1. Región V Altos Tsotsil Tseltal, Chiapas, México

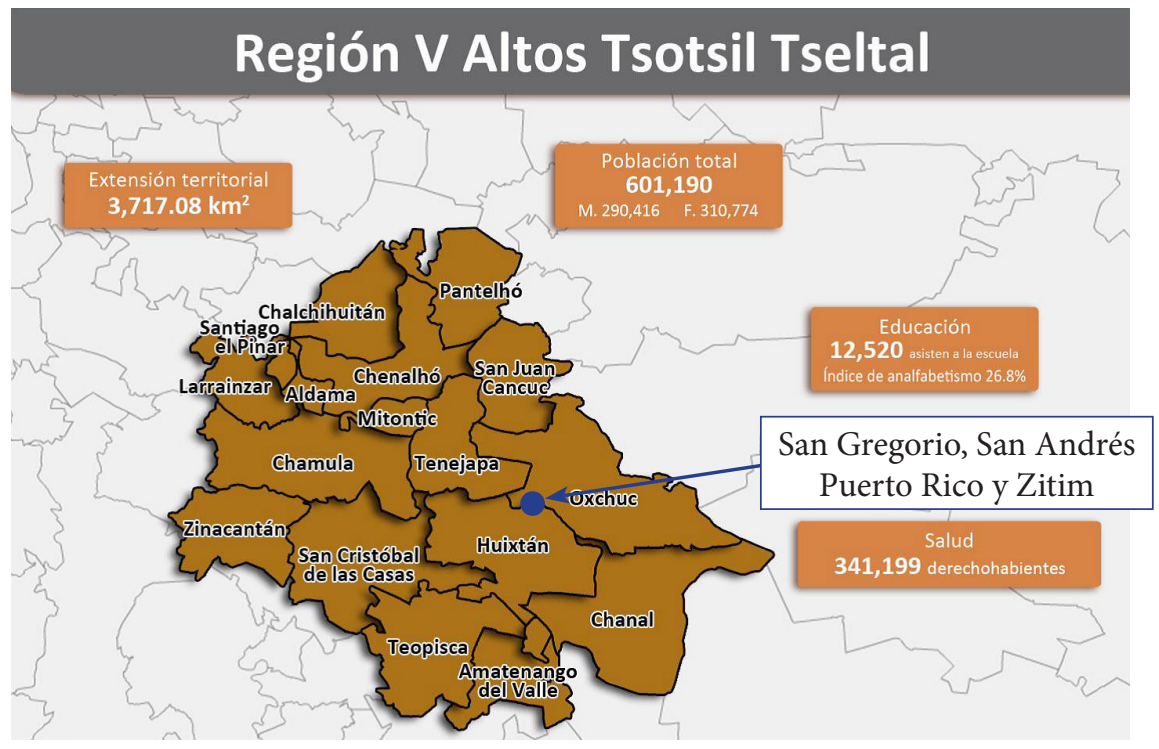

Fuente: Instituto Nacional de Estadística y Geografía (INEGI). Agenda Estadística Chiapas 2010. Comité Estatal de Información Estadística y Geográfica (CEIEG) 2010.

Si bien estas localidades están habitadas por tsotsiles, tseltales y ladinos, ${ }^{2}$ en la población de San Andrés Puerto Rico predominan los segundos, en tanto que en San Gregorio y Zitim la población está conformada en su mayoría por tsotsiles y algunos tseltales, mientras que algunas familias están integradas por miembros de ambos grupos lingüísticos.

\section{La propiedad de la tierra}

En atención a que don Andrés Huacash confirmó que antes del establecimiento de los kaxlantik en las inmediaciones de San Gregorio - específicamente en San Andrés, por ahí de la década de 1940 - hubo ladinos (kaxlantik) en la región, y en consideración a que Justus Fenner ${ }^{3}$ nos aseguró que hubo propietarios de dichos predios al final y posterior a la independencia de México, pudimos, al respecto, recabar los siguientes datos.

Palomo (2007), a partir de una pesquisa de archivo, apunta que en 1772 las haciendas de San Pedro Pedernal y San Gregorio, productoras de trigo, maíz, frijol, ganado vacuno y caballar, no formaban parte de las otorgadas a los naturales de Huixtán, sino que eran propiedad del Convento de Santo Domingo en San Cristóbal (2007: 7). Sin embargo, dichos predios estaban habitados exclusivamente por población originaria "no habiendo 'Gente de otra nación”" (2007: 6), lo

\footnotetext{
${ }^{2}$ El término ladino refiere a mestizos que cotidianamente interactúan con población originaria.

${ }^{3}$ Historiador investigador adscrito al Centro de Investigaciones Multidisciplinarias sobre Chiapas y la Frontera Sur de la Universidad Nacional Autónoma de México (CIMSUR-UNAM).
}

EntreDiversidades. Revista de Ciencias Sociales y Humanidades, vol. 8, núm. 1 (16), enero-junio 2021. Páginas: 258 - 276 ISSN-e: 2007-7610. https://doi.org/10.31644/ED.V8.N1.2021.D01 
que nos orienta hacia la presencia de esta población desde fechas muy anteriores. Más adelante, en el citado documento, Palomo explica:

El primero de septiembre de 1826 se publicó una ley sobre terrenos baldíos, cuyo art. 1 ordenaba que "Todos los terrenos baldíos o nacionales y de propios excepto los ejidos necesarios de los pueblos se reducirán a propiedad particular" (Colección de las leyes agrarias 1878: 3-5, citado en de Vos 1997: 250) (Palomo, 2007: 13).

$[\ldots]$

Esta ley representaba una amenaza real para las propiedades comunales, ya que se abría la posibilidad de que cualquier persona pudiera reducir a su propiedad los terrenos baldíos y de propios de los pueblos (Palomo, 2007: 13).

[...]

Desde hacía algunos años, antes incluso de que finalizara el régimen colonial, se advertía en el ambiente una cierta tendencia a terminar con la propiedad comunal "por el bien de los pueblos y el fomento de la agricultura e industria, y queriendo al mismo tiempo proporcionar con esta clase de tierras un auxilio a las necesidades públicas, un premio a los beneméritos defensores de la patria, y un socorro a los ciudadanos no propietarios", como rezaba en el decreto de 4 de enero de 1813, donde además ordenaba en su art. 1 que:

Todos los terrenos baldíos o realengos, y de propios y arbitrios con arbolado y sin él ... excepto los egidos necesarios a los pueblos, se reducirán a propiedad particular, cuidándose de que en los de propios y arbitrios se suplan sus rendimientos anuales por los medios más oportunos, que a propuesta de las respectivas diputaciones provinciales aprobarán las Cortes (Colección de los decretos 1829, citado en Palomo, 2007: 13-14).

[...]

En 1829, cuatro indígenas del pueblo de Huixtán —Miguel Santis, Miguel Méndez, Domingo González y Pascual Álvarez- compraron la finca San Pedro Pedernal, junto con la de San Gregorio, en $\$ 6$ 300. [...] "los cuatro vecinos sacaron la cara en la compra pero no compraron para sí sino para el común”, quienes previamente habían recaudado el dinero para su compra "con dineros del común que se recaudaron de entre todos los vecinos imponiéndose fuertes castigos a los que no quisieron contribuir" (Palomo, 2007: 8-9).

Respaldados en la ley arriba citada, los terrenos les fueron disputados por "Ciriaco Aguilar, vecino de San Cristóbal con intereses en el pueblo de Huixtán” (Palomo, 2007: 13).

En 1846 Ramón Trujillo, en ese tiempo autoridad en la región, realizó despojos en lo que se conoce hoy como San Andrés. En 1848 los naturales de Huixtán reclamaron los títulos de la Hacienda aduciendo que:

Les habían quitado parte de los terrenos pertenecientes a la misma, entre ellos el ex prefecto don Miguel Trujillo, quien "valiéndose de la autoridad nos quitó otra parte de los terrenos ya referidos y nos ha quitado todos los regadillos que pertenecen a la misma hacienda, cortándonos el agua". Cinco días más tarde, pidieron que el citado Trujillo suspendiera "la formación de ranchos y

EntreDiversidades. Revista de Ciencias Sociales y Humanidades, vol. 8, núm. 1 (16), enero-junio 2021. Páginas: 258 - 276 ISSN-e: 2007-7610. https://doi.org/10.31644/ED.V8.N1.2021.D01 
el trabajo en nuestros cultivos por ser contra ley”. [...] las justicias de este pueblo en unión de los que llaman principales y demás naturales demandaron ante el juzgado de primera instancia que don Miguel Trujillo se hallaba construyendo casas y corrales en el paraje nombrado San Andrés. Este terreno se encontraba entre las tierras de la hacienda San Pedro Pedernal y las del pueblo, y en caso de que fueran nacionales, ellos "son los preferentes por tener antigua posesión de ellas [...] en atención a que tienen sus animales y sementeras que con esto subvienen a sus necesidades, pagos de sus contribuciones y demás obvenciones que tienen” (Palomo, 2007: 18).

Finalmente, después de que los demandantes insistieran varias veces ante la instancia judicial, Trujillo abandonó, quedando San Andrés como parte de San Gregorio (Palomo, 2007: 19). Es importante mencionar que aun cuando en diferentes momentos propiedades de lo que hoy conforman San Andrés Puerto Rico y San Gregorio pertenecieran a criollos o ladinos, hasta la década de 1940 solo fueron poblados por tsotsiles y tseltales.

\section{De la llegada de los kaxlantik ${ }^{4}$}

Según señaló don Andrés, el ejido San Gregorio se fundó como resultado de la política gubernamental de repartición de tierras emprendida a partir del periodo presidencial encabezado por Lázaro Cárdenas (1934-1940), predio que no fue regularizado hasta 1984.

La dotación incluye lo que hoy es la localidad de San Andrés Puerto Rico, que colinda al poniente con San Gregorio y con Celepat al suroeste. Estas, debido a factores que abordaremos más adelante, quedaron fuera del ejido.

Según don Andrés, su abuelo le narraba que no había ladinos por el rumbo antes de los padres de los que hoy habitan San Andrés. Al respecto, los autores inferimos que dichos asentamientos iniciaron en forma paralela a la de Oxchuc en la década de 1940.5 Los kaxlantik que se hicieron de las tierras eran arrieros que llegaron a vender "a plazos" ropa, herramientas y algunos alimentos, pero, sobre todo, pox (aguardiente).

De entre los arrieros que encabezaron el grupo, don Andrés subrayó el nombre de Andrés Trejo, quien destacó porque los tsotsiles contrajeron deudas con él, las cuáles fueron cobradas apropiándose de los terrenos que habían quedado como "testigo" o garantía del crédito, haciéndose con ello de una enorme extensión de tierra:

[...] casi la mitad de San Andrés, donde es San Andrés ahorita, casi tenía todo ese terreno, logró adueñarse de todo ese terreno. Después, les fue repartiendo a sus hijos, a su yerno. Sí, ese señor era bien rico, tenía mucho dinero. Tenía caballos, mulas, machos toros y muchos mozos. Este señor, Andrés Trejo, fue un arriero. Como ellos llegaban a vender trago, fajas como [las que]

\footnotetext{
${ }^{4}$ El sufijo "tik" implica pluralización tanto en tsotsil como tseltal. Por otro lado, la palabra kaxlan es utilizada por los mayas de los Altos de Chiapas para referirse a los ladinos, que en tsotsil y tseltal literalmente significa gallina.

${ }^{5}$ Harman (1990: 28-29) reportó que en la década de 1940 en Oxchuc, tal como en San Gregorio, los kaxlantik se fueron lentamente apropiando de la tierra mediante el cobro de deudas, partiendo del centro de la cabecera municipal hacia la periferia.
}

EntreDiversidades. Revista de Ciencias Sociales y Humanidades, vol. 8, núm. 1 (16), enero-junio 2021. Páginas: 258 - 276 ISSN-e: 2007-7610. https://doi.org/10.31644/ED.V8.N1.2021.D01 
utilizábamos nosotros, que utilizaban más los mayoles que les dicen, los que trabajaban en la presidencia, y como estaban bien caras... Y como en ese tiempo era obligado hacer fiesta, el que le tocaba, pues era obligado a hacer la fiesta y sacar todo el dinero, y ellos iban a prestarle dinero, a comprarle lo que vendía, y como nosotros como campesinos no podíamos pagarlo, como nosotros teníamos terreno, pues lo que dábamos de testigo era el terreno y así cuando no se lograba pagar, pues nos pedía la firma e hizo su papel, y así se fue adueñando de los terrenos que ahora ellos tienen. Así se fueron adueñando.

También otro señor que se llamaba Onofre, ahí donde creció mi papá, él fue su patrón, y él lo que hacía era arrear doce, catorce, quince mulas que traía desde Comitán cargadas de fajas, panela, pox que traía en barril. Todo, todo venía de Comitán en caballo, en mula, en macho y saber qué edad tenía mi papá y así venía trabajando. Y ese difunto señor, su patrón, cuando ya estaban llegando en Celepat, ese señor pasaba con su caballo ya para ordenar hacer la comida, y ya cuando ellos llegan en la casa, pues llegan a descargarle sus cosas y entraban a comer. Y ya cuando terminaban de comer, descargan y descansan. También decía mi papá, que aquí más abajo, donde [el señor Onofre] tenía potreros, ahí llegaban a soltar los caballos, burros... y ya cuando dejaban los caballos y todo regresaban a sus casas a descansar un poco. Y así se fueron introduciendo esos kaxlantik y no sabemos en realidad dónde es su punto de origen. La verdad no sé decirles de qué parte de verdad vienen.

Otra forma de exacción utilizada por los kaxlantik era dar la opción de pagar por el trabajo realizado por sus peones con trago $(p o x)$ :

Y cuando íbamos a trabajar en el trabajo de ellos cada vez que terminamos siempre nos daban trago, y nosotros, los que llegaban a trabajar, primero nos da un poco para calentarnos, como para tener sabor, y luego cuando a nosotros ya no nos bastaba, pedíamos más, pedíamos fiado y lo que ellos hacían, pues, nos da, pero ya después lo pagamos con trabajo y así automáticamente pagamos nuestro trago sin que nos beneficiara. Sí, como mozos, así veníamos trabajando a cambio de trago nada más.

\section{Antecedentes del liderazgo de don Andrés Huacash}

\section{Infancia y adolescencia}

Don Andrés inicia su historia narrando que ingresó a la escuela aproximadamente a los cinco años. De dicha experiencia destacó que tanto los comités de educación como los profesores consentían el ausentismo de los niños, situación que, como se verá más adelante, prevaleció hasta que él accedió al cargo de presidente de dicho comité. En su caso, cuando tuvo edad para trabajar en la milpa, su padre se las arregló para que solo fuera dos o tres días a clases, no importándole que él deseara acudir a la escuela y aprender.

EntreDiversidades. Revista de Ciencias Sociales y Humanidades, vol. 8, núm. 1 (16), enero-junio 2021. Páginas: 258 - 276 ISSN-e: 2007-7610. https://doi.org/10.31644/ED.V8.N1.2021.D01 
[...] cuando ya podía hacer la limpia en la milpa y ayudar a mi papá, ya no me mandaba a la escuela y los maestros no dicen nada y el comité de educación tampoco. Como tomaban, pues mi papá ya lo hablaba al comité, le daba su trago y ya no dice nada, y por eso nada más voy dos o tres días, porque mi papá ya quería que yo lo ayudara, por eso ya no iba bien en la escuela.

Una vez terminado el estudio, el deseo de don Andrés de formarse como profesor fue a su vez impedido por su padre, quien lo forzó a trabajar en el campo.

Y así fui creciendo... y yo quería seguir estudiando como el maestro Antonio, porque él fue mi compañero... y el otro Antonio Gómez en Celepat ya estaba grande, hasta ya tenía su mujer y siguió estudiando, se fue en Huixtán a estudiar, fue a acompañar a un padre y así poco a poco fue estudiando y salió como maestro, como el Antonio Gómez Álvarez, él fue hasta Zinacantán. Y ese señor quería que yo fuera también, y como mi papá no quería mandar y él me decía que yo escapara, y como yo respetaba a mis papás, no me escapé, aunque él me estaba convenciendo que escapara también con él para que nos vayamos a estudiar. No le obedecí. Así fue como me quedé aquí en el campo y no seguí estudiando, y por eso él fue maestro. Si yo hubiera seguido, tal vez fuera maestro.

Otra de las experiencias que marcó su niñez y, en adelante, su vida, gravita en torno al ámbito de la religión y las situaciones que se suscitaron en la iglesia de San Andrés, a la que asistía por no contar con un templo en San Gregorio: "Cuando crecí, cuando tenía la edad de seis, siete años, ya recordaba muy bien que cuando íbamos en la iglesia de San Andrés nos enseñaban a hacer oraciones, a persignar, los mandamientos, nos enseńaban las señoras”.

Como la misa y otras actividades tenían lugar los domingos, sus padres, a pesar de no profesar e incluso oponerse a la iglesia por ser tradicionalistas, permitieron a don Andrés y sus hermanos asistir a los servicios:

Mi papá, mi mamá, nunca llegaron a la iglesia, solo nosotros como niños sí nos daban permiso de llegar a la iglesia. Y cuando ya aprendí a hacer oración, los mandamientos, ya los trabajadores de la iglesia me dijeron que ya podía hacer mi comunión y que mis papás me pasaran comunión, en mi primera comunión y les dije a mis papás que si podía yo, que me dieran permiso de hacer mi primera comunión, así pasé mi primera comunión. Solo me dieron permiso, pero nunca me acompañaron porque mis papás no querían entrar en la iglesia.

Al tiempo fue invitado a formarse como catequista, pero como ello era contrario a los intereses de su padre se vio forzado a declinar, así como con la educación.

Sí, cuando ya estaba más grande hay unos señores, como don Nicolás García que ya murió, mi padrino Andrés Huet. Ellos son los de la zona y como catequistas que llegaron a predicar en diferentes comunidades. Y ellos me llegaron a invitar que yo participara como catequista o como ayudante de la iglesia, pero como yo recibí el orden de mis papás, pues no podía ser,

EntreDiversidades. Revista de Ciencias Sociales y Humanidades, vol. 8, núm. 1 (16), enero-junio 2021. Páginas: 258 - 276 ISSN-e: 2007-7610. https://doi.org/10.31644/ED.V8.N1.2021.D01 
porque depende de lo que mis papás me dicen. Lo único que responde mi papá cuando llegan esos señores en nuestra casa a invitarme a que yo participara como ayudante, mi papá nada más dice a esos señores que: "Le voy a decir a mi hijo, a ver qué piensa". Pero nada más así, pero en realidad es que no me quiere dar permiso porque nunca le gusta la iglesia a mi papá, nunca le gustó entrar en la iglesia. Y los señores pues seguían insistiendo de que yo participara como ayudante nada más y así poco a poco perder el miedo y seguir trabajando con ellos, pero mi papá no me daba permiso.

\section{Presidente del comité de educación}

La labor de don Andrés se empieza a definir cuando aún joven, al poco de casado, recién incorporado como ejidatario y sin haber tenido ninguna responsabilidad social previa de menor jerarquía, como era la costumbre, fue nombrado para encabezar el comité de educación del ejido.

Su desempeño infatigable y estricto al frente del comité cimentó su posterior liderazgo ante la comunidad. Gestión que ante todo se caracterizó porque no permitió que los niños faltaran a la escuela:

Yo entré en ejidatario cuando ya estaba casado. No me acuerdo bien si ya tenía mi primer hijo, pero ya cuando entré ejidatario, ya me nombraron luego como comité de educación. Y cuando yo era comité de educación, los maestros eran puros kaxlantik. Y cuando yo entré en educación como que no me gustaba que los alumnos no llegaban a estudiar, como que no se ve bien que no llegaran a estudiar y los otros de educación que pasaron no les importaba. Y yo, cuando entré, como que no me gustó, y aquel tiempo ya empecé a presionar que tenían que mandar a sus hijos en la escuela. $\mathrm{Y}$ así fui presionando que tenían que mandar a sus hijos en la escuela.

Me decía mi papá que me cuidara, porque tenía mis comisiones y las comisiones su trabajo era pasar los avisos en cada casa y si algo no se cumplía, ellos, los comisiones, iban en la casa a avisarlo. Y me decía mi papá que yo no los mandara porque ellos son mayores "y aunque sean tus comisiones, pero no debes decirles nada", "y si lo que yo quiero tengo que ver si es justo o no”. Y como antes se hacía fuego en las comunidades, ellos iban a pasar en las comunidades a dar la invitación y me decía mi papá que no les hablara tanto a mis comisiones porque son mayores que yo, y que son muy peligrosos porque ellos pulsan, eran pit'chich (el que puede ver y escuchar la sangre al pulsar), y si yo les digo lo que hacen pues se pueden enojar, me pueden hacer alguna maldición. Eso me decía mi papá que yo tenga cuidado, porque yo era el menor de todas las comisiones. Y como yo soy el comité de educación, pues yo daba el orden de lo que se tenía que hacer. Pero yo le digo a mi papá que lo que les digo pues es justo y mientras que es razonable lo que les digo, todos les tengo que decir así parejo, no uno o dos nada más que le digo, sino que a todos sea igual lo que yo les digo, no solo uno, todos los molesto. Y gracias a dios esos señores sí obedecían.

También durante su cargo gestionó y obtuvo ante la Secretaría de Educación la primaria completa para San Gregorio: “[...] y pedí también que la primaria haya completo, porque antes no había completo y yo solicité que estuviera completo la primaria, hasta en sexto grado".

EntreDiversidades. Revista de Ciencias Sociales y Humanidades, vol. 8, núm. 1 (16), enero-junio 2021. Páginas: 258 - 276 ISSN-e: 2007-7610. https://doi.org/10.31644/ED.V8.N1.2021.D01 


\section{Comisariado ejidal}

Fue tan buena la impresión que causó ante la comunidad, que poco tiempo después de terminar su mandato como comité de educación, en 1984, a los 24 años, fue nombrado comisariado ejidal: "Era el acuerdo del ejido, como ejidatario el acuerdo era de ser comisión de educación, después de ser educación era descansar tres años. Pero lamentablemente no sé cómo me vieron la gente, si sabían que yo pensaba más o que movía yo a la gente. Todavía no alcanzaba los tres ańos y me agarraron como comisariado".

\section{Partero y promotor de salud}

Todavía fungiendo como comisariado siguió activo en la iglesia. Al término de su mandato fue nominado para capacitarse como partero y promotor de salud, lo que constituyó un importante apoyo para las mujeres de San Gregorio, debido a que tenían que trasladarse a San Andrés, hecho que implicaba, además de más de una hora de camino en cerro, ser atendidas por las ladinas.

Por ejemplo, yo, cuando no sabía partero, como tuve mis hijos también, lo que hice fue avisarles a las señoras de San Andrés, porque algunas son las que saben, son parteras y saben ver a un bebé cuando nace. Pero lo que hacen ellas es que no les importa si se muere o no, porque en realidad se murieron dos hijos míos que en realidad fue error de la partera. Y así en muchas partes sucede eso, no solo a mí me pasó, en muchas partes se murieron niños, porque a esas señoras no les importaba, como que no nos tomaba mucho en cuenta.

El principal impedimento que don Andrés anteponía para capacitarse era que no sabía leer ni escribir, lo que consideraba imprescindible para formarse; pero al respecto se le dijo que no lo necesitaba.

Y ahí fue que me fui, y como no sabía ni leer ni escribir, antes no sabía nada, hasta la lectura no podía leerlo: “¿Y cómo, si no sé hacer nada, no puedo aprender nada?". Me dijeron que no era necesario: "Lo que escuchas, lo que puedes escuchar, con eso te va a servir". Y como nadie quería ir, ahí decidí que mejor voy a intentarlo y anoté mi nombre.

Con lo que nos dijeron ahí pude atender y ya poco a poco aprendí a leer y a escribir. Pero como nos dijeron el libro no sirve cuando estamos dando consulta, sino que lo que aprendes aplicas y practicas ya te queda y te vas a ir capacitando más, vas a ir viendo, observando, y si no practicas, aunque tienes libros, pues no te ayuda a dar consulta, aunque solo te ayuda en tus dudas. Por eso creo que eso es lo importante de estar practicando, no es necesario tener muchos papeles, si no practicas no serviría de nada.

En su desempeño en el ámbito de la salud, no descuidó, conforme envejecía, motivar al menos a dos de sus hijos a encaminarse en la atención de los enfermos y las mujeres embarazadas. Tanto es así que en la actualidad dos de sus hijos son promotores herbolarios de salud y una de sus nueras, partera, y juntos fundaron y encabezan la clínica autogestiva de Zitim, que además se

EntreDiversidades. Revista de Ciencias Sociales y Humanidades, vol. 8, núm. 1 (16), enero-junio 2021. Páginas: 258 - 276 ISSN-e: 2007-7610. https://doi.org/10.31644/ED.V8.N1.2021.D01 
ha ocupado, con el apoyo de diferentes profesionales locales y de otras partes del mundo, de capacitar a jóvenes de la misma comunidad y de varios municipios de Chiapas.

Más adelante y con detalle se tratará el desempeño de Andrés, años más tarde, en lo que él denomina la "palabra de dios".

\section{De la dotación ejidal y sus vicisitudes}

A partir de este apartado se abordarán diferentes vicisitudes que, con don Andrés al frente, enfrentó la población de San Gregorio con los kaxlantik de San Andrés, tanto en el plano de lo político como en el de la incidencia a través de la "palabra de dios", en el combate al consumo de bebidas alcohólicas.

El desconocimiento por parte de los ejidatarios de San Gregorio respecto a las leyes sobre el ejido, la falta de la carpeta básica que establece los límites de la dotación del ejido y la premura por pagar sus deudas provocaron que los tsotsiles fueran poco a poco cediendo las tierras donde hoy se asienta la localidad de San Andrés.

Fue hasta que don Andrés Huacash fungió como comisariado ejidal, cuando por su iniciativa se solicitó la delimitación del ejido y se tramitó la carpeta básica:

Y ya cuando fui a México, ya en la segunda vez, ya me mostraron el plano, y ya ahí nos dijeron que por qué permitimos, que San Andrés también pertenecía a San Gregorio, era terreno de San Gregorio, y ya nos dijo el ingeniero en México: "¿Por qué permitieron que se apartaran del terreno?". "Si ellos no querían estar con ustedes”, que “¿por qué no salieron?”. "No es para que ustedes les hayan dado derecho de quedarse con el terreno, son sus tierras, pues". Y me preguntó quién había sido el comisariado, y como ese comisariado de antes iba conmigo, mi primo, y ya le dijeron que no estaba bien lo que hizo, que permitiera. Que no debe ser.

Lo mismo les dijeron sobre Celepat, comunidad que había optado por separarse de San Gregorio y conformar su propio ejido.

Una vez informados los ejidatarios de la situación, en un principio se inclinaron por recuperar esas tierras, lo que implicaba enfrentamientos con los habitantes de los otros dos poblados. Finalmente, después de una larga discusión, se decidió aceptar la separación y conformar el ejido con lo que quedaba. "Y yo ya calmé porque era más problema y ya les dije a la gente que mejor que se quedara así, que si ya se quisieron apartar, pues que hagan su propia comunidad, que nosotros viéramos el terreno que nos pertenece, y ya fue que quedó así”.

Actualmente, el ejido de San Gregorio

[...] es bastante grande, el terreno de San Gregorio colinda con el terreno de Xunkala, da vuelta hasta el río donde le llaman río de Chiapas, así le llamaban a ese río, ahí da vuelta, de ahí hasta pasa en un lugar que se llamaba Ch'en ik y llega a colindar hasta aquí en Zitim, y así va dando la vuelta y es bien grande el terreno del ejido de San Gregorio.

EntreDiversidades. Revista de Ciencias Sociales y Humanidades, vol. 8, núm. 1 (16), enero-junio 2021. Páginas: 258 - 276 ISSN-e: 2007-7610. https://doi.org/10.31644/ED.V8.N1.2021.D01 
Antes de que se lograra obtener la delimitación del ejido y la carpeta básica, los ejidatarios tuvieron problemas de límites con las comunidades tsotsiles de Pozos y Duraznal: la primera, ubicada al sureste, a pesar de que sí contaba con su propia dotación; los terrenos del Duraznal, situados al noroeste, quedaban dentro de la dotación de San Gregorio, problema que resolvieron las partes aceptando la separación y fijando los límites entre uno y otro. Una vez establecidos legalmente los límites, terminaron los problemas con los vecinos, con quienes en adelante se ha vivido en paz.

Y como cuando era comisariado don Alonso con el de Duraznal no podían hacer nada. Hasta los de Duraznal un tiempo llegaron en la comunidad, según a arreglar el problema, y como la gente de San Gregorio estaban bien encabronados también y se agarraron a golpes, y como los de San Gregorio eran bastantes, los de Duraznal no eran bastantes, eran menos que los de San Gregorio y bien que los dejaron bien golpeados y los metieron en la cárcel.

Ya cuando yo estaba ahí, que era comisariado, vino el peritaje, y se vio que era negativo y fue aprobado de San Gregorio que es nuestro terreno, y el ingeniero que vino a hacer el peritaje dio el informe de que era verdad nuestro terreno y pidió que lo levantáramos un papel. Y ya me mandaron en México.

Con los conflictos resueltos, la dotación ejidal bien delimitada y habiendo obtenido la carpeta básica en 1984, en 1988 varios ejidatarios de San Gregorio, incluida la familia de don Andrés, compraron una fracción de terreno al poniente del ejido, predio que se conoce como Zitim, cuyos habitantes siguen considerándose parte del ejido de San Gregorio, ya que los propietarios fundadores conservan su derecho como ejidatarios, manteniendo su presencia en el fundo y parcela: “... y también como nosotros no queríamos vivir en el centro, porque era ejido, ya compramos este terreno para venir acá en Zitim con tu abuelito. Sí, así fue”.

\section{La estrategia para detener los abusos de los kaxlantik}

Uno de los mayores problemas que don Andrés confrontó y resolvió durante el cumplimiento del cargo de comisariado ejidal fue el persistente racismo y maltrato que tsotsiles y tseltales sufrían a manos de los kaxlantik, a los que, entre otras cosas, tenían que "respetar", fueran estos niños, jóvenes, adultos o ancianos. El "respeto" consistía en que al paso de alguna de las personas señaladas estaban obligados a quitar los sombreros para saludar, dirigiéndose al otro como kajhual, término que podría traducirse como patrón o jefe. Esto además de otros abusos, como golpearles y robarles sus pertenencias:

También así son los kaxlantik que teníamos que respetar, si pasábamos en su casa lo teníamos que respetar, quitar nuestro sombrero, hasta decíamos kajhual, le decíamos, así como respeto, pues, a los señores. Hasta no solo los señores, hasta sus hijos los teníamos que respetar. Aunque seas ya de mayor edad tienes que respetarles a sus hijos. Así nos humillaban.

Si no sabíamos hablar nos decían: "pendejos indios", nos decían, y así como que no, como también no sabíamos hablar. Más con mis abuelos que pasó eso, que no sabían hablar el español,

EntreDiversidades. Revista de Ciencias Sociales y Humanidades, vol. 8, núm. 1 (16), enero-junio 2021. Páginas: 258 - 276 ISSN-e: 2007-7610. https://doi.org/10.31644/ED.V8.N1.2021.D01 
casi ni entendían también, por eso los humillaban tanto. [Además] no podías hacer nada, ni sembrar, y si ven que están los animales cerca del mojón, te empieza a regañar, y si llevas hacha, reloj, lo que sea, pues te quita, aunque no estás dentro de su terreno, o si no te quita algo, te da chicote.

Otra situación de no menor importancia que los ejidatarios enfrentaron, refiere a que los kaxlantik dejaban libre el ganado y animales de carga para que deambularan con libertad por todos los terrenos de la población maya, entrando en las milpas de unos y otros según sus apetencias:

Ellos sueltan sus caballos sin importar que entraran en nuestra milpa. Si no alcanzabas a llegar en la mañana, pues ya entraban a comer los caballos y si encuentras caballos, pues voy a devolver nada más, no les dices nada, pues si les dices algo pues se enojan, te regańan. Pero mi papá no se dejaba también, a veces le pagaban, a veces ya no le pagaban. Y así era, teníamos que respetar. Teníamos un terreno cerca del terreno de ellos que daba bien el maíz y si no te apurabas, siempre así llegaban los caballos a comer todo y casi no podías hacer nada, pues si empiezas a regañar o quisieras regañar, pues ellos te pegan y todo. No es como ahora que ya no hacen nada, no pueden hacer nada.

Respecto de esta situación don Andrés narró una experiencia que su familia tuvo con un vecino kaxlan:

Cuando yo era comisariado, hay un rancho aquí cerca, el dueño se llamaba Horacio, era un maestro, tenía sus animales también, tenía vaca, becerros, así. Como colindaba con mi terreno, sus animales entraban a comer en mi milpa. Tenía un mayordomo tseltal que se llama Carmen Ton. Íbamos a llegar a avisarle, pues, y él dice: “Ah, no te preocupes, lo vamos a pagar”. Y nada más así dicen y no pagan. Y llegaban a comer la milpa, y así muchos señores: don Miguel Pérez, Miguel Bolóm, los Moshanes tenía milpa cerca de ese rancho, pues casi ya ni se podía sembrar. Si siembran, pues ya los animales llegaban a comer y no les pagaban, casi no cosechaban nada [...] no puedes hacer nada, como ellos tienen dinero, te demandan y todo eso, y ya te llaman hasta en el ministerio y tú pagas todo lo que no le gusta, lo poquito que sea.

Para don Andrés esta situación era intolerable, por lo que sometió el asunto en la sesión de consejo, donde se acordó proponer a los ejidatarios en asamblea "atrapar" a esos seńores y obligarlos a pagar y respetar:

Pero yo decidí esto y ya busqué la manera, pues el Carmen Ton que estaba cuidando el rancho pasaba los mojones con su machete, con un arma para ver qué pasaba. Y también el dueño, el maestro Horacio, llevaba un su cuchillo o un su 38 y no podías hacer nada. Ya con eso asustaba. Ahora, cuando teníamos el plan ya fuimos a platicar con el presidente municipal para ver qué nos dice, si nos podía apoyar. Después consultamos con la gente qué pensaban. El plan era que entrara un animal, lo agarramos el animal y que tenía que entrar el dueño del animal, de los

EntreDiversidades. Revista de Ciencias Sociales y Humanidades, vol. 8, núm. 1 (16), enero-junio 2021. Páginas: 258 - 276 ISSN-e: 2007-7610. https://doi.org/10.31644/ED.V8.N1.2021.D01 
toros, el señor Horacio o el caporal que llegara a sacar su toro. Y el plan era que cuando entrara agarrarlo y quitarle su arma o lo que llevaran y meterlos en la cárcel hasta que lo paguen y firmen un papel de que ya no hicieran eso. Y cuando lo pagan y de que hasta que firmara podía salir de la cárcel, aunque ellos pelearan y nos lleven al ministerio y nosotros llevamos el arma para demostrar que ellos usaban esto. Que ya sabemos que una vez que llega en el ministerio el arma ya no nos lo mandan, ya se queda ahí en el ministerio, ya no lo regresan, y ya le dijimos el juez y nos dijo que estaba bien.

Porque eso es lo que dice la gente también, que sí están de acuerdo con apoyar un poquito, “porque, ¿hasta cuándo nos defenderemos?”. Les dije que si acaso nos gusta que siempre nos maltratan y nos hacían lo que quieren, porque ya no podíamos sembrar, pues ahí por esa razón que lo acaba pues la milpa con sus animales. Y yo les dije que nos apoyaran si se hacía gasto y todo o si nos íbamos a la cárcel, pues que ellos nos apoyaran para sacar con dinero y todo. Y como ya teníamos el permiso del presidente, pues ya el presidente nos apoya también si se llega a suceder algo y teníamos fuerza, pues, para hacer eso.

Con objeto de fortalecer la iniciativa, se obtuvo el apoyo de los profesores que ya en ese tiempo eran tsotsiles. Además, se encargaron de elaborar los documentos que se requerían para zanjar el asunto.

El día de los hechos, atraparon un toro que se alimentaba en una de las milpas de San Gregorio. Tan pronto se enteró el caporal del profesor, llegó a la casa del dueño de la milpa a reclamar su ganado, cayendo en la trampa que se le había tendido:

Uno lo habló y otros lo atraparon por la espalda y lo agarramos y lo llevamos a la comunidad. Y cuando lo agarramos, le quitamos su arma y lo metimos a la cárcel en esa misma comunidad. Y ya él se empezaba a asustar, [nos dijo] que no hiciéramos eso porque él no era el dueño del rancho. Que dio el alambre donde colindábamos, pero nosotros hacíamos los postes y si pasaban los animales decía que era nuestra culpa que nosotros no estábamos cuidando el alambrado. Y siempre así nos echaba la culpa. Pero cuando lo agarramos este caporal lo mandamos a la cárcel y le dijimos que pensara todo lo que está haciendo y si quería pagar todo lo que han hecho se sale de la cárcel. Lo sacamos y finalmente lo arreglamos así, levantamos actas y ya el dueño del rancho nunca se acercó, pero finalmente ya él mismo firmó y que al firmar dijimos que tenía que pagar todo lo que nos había hecho, pues lo tuvo que pagar todo. Cuando lo encarcelamos todo lo pagó, todo.

Pues así fue como logramos que nos respetara el dueño del rancho. El ranchero que colindaba con nosotros, sus animales ya no pasaban, ya no podía pasar, si pasaba ya sabe que paga, ya respetaba.

Si bien la difusión de este hecho bastó para dar fin a la situación narrada, los kaxlantik recurrieron a otros mecanismos para hostigar a la gente de San Gregorio. Entre otras cosas, destaca que como resultado de una quema que un campesino llevó a cabo para preparar su terreno para la siembra, el incendio se propagó hacia una de las parcelas del profesor, afectando sembradíos y bosque.

EntreDiversidades. Revista de Ciencias Sociales y Humanidades, vol. 8, núm. 1 (16), enero-junio 2021. Páginas: 258 - 276 ISSN-e: 2007-7610. https://doi.org/10.31644/ED.V8.N1.2021.D01 
[...] y él nos presionaba a pagar porque si no, que llamaba al forestal para que pagáramos y que iríamos en la cárcel también.

Para que no nos metiera forestal, él pidió que su carretera pasara en nuestro terreno donde podía pasar con su carro, porque también en San José no le daban permiso también y con esto de que quemamos su tierra, para que no nos demandara le tuvimos que dar chance de que hiciera su carretera y que hiciera la brecha. Y sí, sí le dimos el permiso de que hiciera su carretera. También levantamos actas ahí de qué tanto es el tamaño de la carretera, porque normalmente es de seis metros que mide de ancho la carretera, y sí, sí le dimos.

Este hecho coincidió con los preámbulos del levantamiento zapatista, por lo que no pasó a mayores.

Pero ya no lo logró hacer, ya se acercaba el levantamiento del 94, y ya esa vez ya no logró hacer su carretera y llegaron los zapatistas y le quitaron, pue', el rancho. Ahora ya no es de él, es de los zapatistas, y finalmente la carretera ya no pudo hacerse, sigue así sin carretera, no puede entrar carro en su rancho. Sí, así pasó con don Horacio, el dueño de ese rancho.

Respecto de la discriminación y maltrato de que los tsotsiles eran objeto por parte de los kaxlantik, fue el colectivo, y no necesariamente inducido por don Andrés, el que se ocupó del asunto sobre el supuesto "respeto", de manera que fue encarado en busca de la dignificación de la identidad de los habitantes de San Gregorio:

Y ya cuando nosotros en nuestra generación que fuimos creciendo y, gracias a dios, que ya medio hablamos la castilla, pues ya con eso como que no nos fuimos dejando, pues, aunque nos querían humillar, pero ya poco a poco no nos dejamos y también ellos nos tuvieron que respetar. Porque antes también nos asustaban con sus pistolas, como tenían dinero, pues ellos nos asustaban con la pistola, que siempre llevan cargada su pistola. Pero cuando ya empezamos a hablar el español un poco ya no nos dejamos y así poco a poco nos fueron respetando. Y como ven ahora, ya no es lo mismo como antes, ya no tienes que decirle kajhual o patrón. Si es necesario a veces ya ni los respetamos también.

\section{La palabra de dios}

Aún con las tensiones derivadas de las acciones encaminadas a contrarrestar a los kaxlantik, al no haber alternativa, la gente de San Gregorio continuó asistiendo al templo de San Andrés.

[...] porque ahí estábamos antes en la iglesia de San Andrés, aun así, en aquel tiempo ya no tanto los respetábamos, porque antes sí los respetábamos mucho. Y hasta sus hijos nos dicen indios y eso a mí no me gustaba.

EntreDiversidades. Revista de Ciencias Sociales y Humanidades, vol. 8, núm. 1 (16), enero-junio 2021. Páginas: 258 - 276 ISSN-e: 2007-7610. https://doi.org/10.31644/ED.V8.N1.2021.D01 
Se precisaba, entonces, como siguiente paso, la gestión, construcción y activación de la iglesia de San Gregorio, que al concretarse significó la separación total entre los pobladores de San Gregorio y San Andrés.

Fueron varios los factores que coadyuvaron a acelerar la decisión, a pesar de que los tsotsiles ya no se sometían ante las demandas de "respeto" por parte de los kaxlantik: por un lado, los domingos cuando asistían a la iglesia no faltaban expresiones racistas como "pinches indios", incluso en boca de jóvenes y niños; por otro, y aunado a ello, para la liturgia y la celebración se utilizaba el español, aun cuando ya la iglesia había instituido los textos en todos los idiomas mayas.

En 1989, un año después de que don Andrés terminara el cargo como comisariado y ya en funciones el templo de San Gregorio, debido a problemas con una ejidataria que se oponía al acuerdo de libre pastoreo y tránsito, y ante la oportunidad de poseer terrenos en los que no tuvieran problemas y restricciones como la señalada, la familia amplia de don Andrés, es decir, sus padres y hermanos, compraron un predio localizado al oriente de San Gregorio, con límites con San Pedro Pedernal, conocido como Zitim, en donde hasta la fecha viven.

Y estuve ahí en la colonia viviendo como un año, un poquito más de un año, y cuando empezó el problema con dońa Petrona Álvarez que no quería que entraran nuestros toros en su tierra, en su terreno que llegan a comer el pasto, le molestaba a ella y a mí tampoco no me gustó y fue cuando decidí de venir hasta acá en Zitim, porque estaba más libre, podía ir con mis toros en donde yo quiera.

Dado que el traslado de Zitim a San Gregorio implica al menos una hora de camino por terreno montañoso, ya que estaban bien asentados en Zitim algunos de los jefes de familia se organizaron para la construcción de la iglesia.

Y ya cuando estaba acá nos dijimos con los que ya estaban acá, platicamos de que si no queríamos hacer la iglesia acá cerca, porque estábamos yendo hasta San Andrés y San Gregorio. Ellos me dijeron que sí queríamos hacer la iglesia acá, organizarnos y ya yo le dije que si quieren eso podemos hacerlo. A mí me gustó su idea, porque estaba bien lejos, como caminábamos hasta allá, para poder llegar salíamos temprano y cuando dijimos así.

Una vez acordado construir la iglesia, dado que don Andrés seguía participando en actividades relacionadas con "la palabra de dios", acudió a los coordinadores de zona con la solicitud.

Como estaba con los coordinadores de zona de la iglesia, pues ya les dije que si nos permitían hacer nuestra iglesia en la comunidad. Y nos dieron permiso y ellos dijeron que iban a pensar con el padre y todo. Y como no era malo pues nos permitieron, solo que como no teníamos iglesia, nos tuvimos que reunir en el campo a escuchar la palabra de dios.

EntreDiversidades. Revista de Ciencias Sociales y Humanidades, vol. 8, núm. 1 (16), enero-junio 2021. Páginas: 258 - 276 ISSN-e: 2007-7610. https://doi.org/10.31644/ED.V8.N1.2021.D01 
Para contar con iglesia en la ranchería se precisaba de presidente y tesorero, de modo que nombraron a don Andrés para el cargo. Además, la parroquia les envío a dos catequistas, de tal manera que aún sin templo pudieron llevar a cabo su actividad religiosa en la comunidad.

Como era de esperarse, don Andrés destacó en las reuniones de presidentes y catequistas en la parroquia de Huixtán, por lo que fue elegido coordinador de zona, cargo que consiste en coordinar presidentes y catequistas de las diferentes iglesias de la zona correspondiente. Desde esta plataforma, inducido por el sacerdote de Huixtán, se embarcó de forma casi obsesiva en la erradicación de las bebidas alcohólicas en la región.

\section{Cruzada contra el consumo de bebidas alcohólicas}

Como autoridades de "la palabra de dios", presidentes y catequistas frecuentemente eran invitados como padrinos de bautizo, primera comunión y bodas. Fiestas y reuniones en las que invariablemente la concurrencia se embriagaba. Ante esto, el párroco de la iglesia de Huixtán condicionó la permanencia de unos y otros en su labor religiosa a renunciar a las bebidas alcohólicas.

[...] y vio el padre Marcelo que eso no se podía ser, siendo que nosotros somos trabajadores, que trabajamos en la iglesia, y como dice la palabra de dios: "no es bueno tomar", y como nosotros predicábamos tenemos que dar el ejemplo de que no podemos tomar. Que nosotros como trabajadores no deberíamos tomar. Nos leyeron una lectura de eso y nos mandó a decidir bien qué es lo que hacemos, qué queremos hacer, si somos los verdaderos predicadores sobre la palabra de dios debemos de dejar el alcohol, y que decidiéramos si queremos dejar o no. Si dejáramos de tomar y de servir el alcohol, pues nosotros seríamos como los verdaderos predicadores de dios y los que decidimos que no podemos dejar ya no podíamos regresar en la iglesia.

Eso nos mandó solo un rato a decidir qué queríamos hacer, para regresar nada más los que decidimos dejarlo, y los que no quisieron pues ya no entraron de nuevo a la iglesia.

La exigencia del párroco fue más allá, conminando a los trabajadores a dejar de asistir a las fiestas.

Y al volver a la iglesia nos dijo el padre Marcelo de que nosotros como trabajadores había que dar el ejemplo, aunque nos den alcohol no agarramos, aunque nos vayamos en las fiestas de nuestros ahijados, pero el padre nos dijo que ya no teníamos que ir, pero nosotros como trabajadores lo valoramos y ya decidimos sin el padre, que tampoco es bueno de no ir, que está bien ir a acompañar a nuestros ahijados, pero que si dan alcohol, nosotros no lo agarramos.

Y de lo que analizamos le dijimos de nuevo al padre, pero él nos entendió que tenemos razón de que si acompańamos a nuestros ahijados y no tomamos no hay problema.

Entre los que aceptaron dejar el "trago", en común acuerdo con el párroco decidieron emprender una campaña contra del consumo de bebidas alcohólicas en el municipio, acción que claramente afectaría no solo los intereses de los kaxlantik de la cabecera municipal, sino de los que se asentaban en diferentes parajes, como era el caso de los de San Andrés.

EntreDiversidades. Revista de Ciencias Sociales y Humanidades, vol. 8, núm. 1 (16), enero-junio 2021. Páginas: 258 - 276 ISSN-e: 2007-7610. https://doi.org/10.31644/ED.V8.N1.2021.D01 
Como primer paso, desde la posición de líderes religiosos lograron convencer a la mayor parte de la población del municipio de elegir un presidente municipal que estuviera a favor de la "ley seca".

Una vez elegido el presidente municipal, idearon una estrategia para evitar que los kaxlantik asociaran al presidente con la campańa que emprendieron:

Para evitar el problema del presidente con los kaxlantik, dijimos que la idea fue de la comunidad para hacer manifestaciones y todo sobre el alcoholismo. Todos los que vendían alcohol eran los kaxlantik. Y cuando fuimos a hacer manifestación ya hicimos así como una estrategia de que nosotros agarramos al presidente ahí en el quiosco, e hicimos como que lo presionamos, pero ya era un plan para que los kaxlantik no pensaran que el presidente estaba de acuerdo con nosotros, para que se viera como que fuera presión en contra de él; pero en realidad el presidente ya sabía el plan y estaba de acuerdo con nosotros.

Hicimos que firmara ahí en el quiosco y después de la firma cada borracho que se agarre nos tendría que decir dónde compró el alcohol. Y ya cuando los borrachos nos dicen, pues nos íbamos hasta en la cantina donde tomó y lo agarramos el dueño, lo agarran los policías del ayuntamiento y lo multan, y así fuimos trabajando.

Todos los kaxlantik de San Andrés, quienes desde que se asentaron en la localidad en parte vivían de la venta de "trago", al ver amenazada su fuente de ingresos recurrieron a varios atentados en contra de don Andrés; de entre estos destacan en su memoria los siguientes:

[...] don Pedro Trejo tenía carro. Él intentó matarme. Me di cuenta un día cuando fui en una reunión, cuando estaba caminando se venía como a chocarme y como la carretera es muy reducida, era más montaña, yo me metí en la montaña y ya me salvé ahí, y como sabían que yo hablaba más, pues querían liquidarme.

En una misa que hacemos cada mes, ahí fuimos a platicar sobre alcohol, porque "los zonas" que estaban en cada zona, por zonas estábamos divididos en la parroquia, y ya nosotros fuimos a platicar, y como nos reconocieron quién estábamos hablando más, pues, vinieron personas a buscarme, personas que venían por López Mateos, por Tulú, y que venían a verme en el camino, a buscarme en dónde me encontraban para matarme.

Un día, por la gracia de dios, andábamos mi compadre Pedro Moshán [y yo], me advirtió, me dio el conocimiento de que alguien me estaba buscando para matarme, porque él mismo, mi compadre, platicó con esas personas que me estaban buscando, que estaban preguntando por mí, que estaban por zona Guadalupe, preguntando por mí, que en qué zona estaba y que mi compadre les preguntó que para qué me buscaban y ellos dijeron de que querían platicar conmigo, pero mi compadre les preguntó de nuevo: “¿Pero qué quieres platicar con él?”, que le preguntó, y ya después fue que hablaron de que querían matarme, porque yo ya fui a platicar por la zona Sagrado, por Chilil, y zona San Miguel, por López Mateos, sobre el alcohol y por esa razón de que querían matarme, y eso dijeron que los habían mandado de que mataran "al zona", o sea que me tenían que matar a mí.

EntreDiversidades. Revista de Ciencias Sociales y Humanidades, vol. 8, núm. 1 (16), enero-junio 2021. Páginas: 258 - 276 ISSN-e: 2007-7610. https://doi.org/10.31644/ED.V8.N1.2021.D01 
En 1994, en el contexto del levantamiento zapatista, el profesor que accedió a la presidencia municipal de inmediato levantó la veda de alcohol. Esto, además, coincidió con el cambio de zonas y coordinadores de la parroquia, quienes, de acuerdo según don Andrés, tuvieron miedo de que los mataran y por lo mismo no continuaron con la campaña en contra de las bebidas alcohólicas. A pesar de ello, en algunas comunidades como San Gregorio y Zitim la ley seca se mantuvo durante aproximadamente una década, a partir de lo cual, con el cambio de autoridades ejidales, se derogó y se retomó la ingesta de alcohol.

Antes, digamos, cuando la comunidad sí estaba muy fuerte sobre el alcohol, ninguna autoridad puede tomar y aquella autoridad que toma pues se multa. Y también, como nosotros de San Gregorio se mantuvo la ley seca, si se agarra a alguien que toma y dice dónde compra, nosotros como los de San Gregorio íbamos a agarrar. Los de San Andrés empezaron a vender todos de nuevo y el borracho que hace el problema y nos dice dónde toma, pues íbamos hasta en la casa de algún kaxlan que vendió el trago, pues lo multábamos, porque la comunidad estaba bien organizada y podía controlarlo, pero ahorita ya no es tanto así. Pues ahora, lamentablemente, pues no se pudo hacer largo la ley seca porque la gente que tiene miedo tenía miedo de morir, ahorita hasta algunos trabajadores de la iglesia ya toman y no les dicen nada ya, porque no hay, digamos, el control como antes.

Aproximadamente con 50 años don Andrés fue diagnosticado con diabetes mellitus, enfermedad que con el tiempo se complicó, razón por la que disminuyó su actividad como promotor y partero, sin cejar en las cuestiones religiosas, constreńidas exclusivamente a la iglesia de Zitim.

\section{Consideraciones finales}

Las últimas décadas del siglo XX se caracterizaron por diferentes movimientos mayas y de campesinos encaminados a lograr respeto y dignidad de sus contrapartes étnicas, "los otros", los kaxlantik. Ya fuera recurriendo a la recuperación de tierras, confrontando paramilitares invasores, o bien poniendo un alto tajante a la explotación, el despojo y el racismo, como es el caso que hemos abordado en este documento. Por encima de todos estos movimientos, obviamente destaca el levantamiento llevado por el Ejército Zapatista de Liberación Nacional en 1994. Sin embargo, la característica fundamental es que los avances solo se lograron anteponiendo violencia a la violencia estructural.

Priorizamos con Bajtín (1999) y Alejos (1994) "la expresión verbal”, "los enunciados" vertidos de manera predominante dando voz a don Andrés Huacash, interesado él y nosotros en exponer hechos que narran las condiciones de vida a que estaban expuestos, en este caso, los tsotsiles de San Gregorio y San Andrés y en un momento dado la agencia que aglutinó fuerza y se contrapuso a los abusos neutralizándolos y, con ello, posibilitando condiciones de vida dignas.

Finalmente, la vida de don Andrés avocada al servicio y lucha por su pueblo constituye un testimonio que desde nuestro punto de vista debe ser resaltado y queda como antecedente y anécdota de sucesos de un pueblo.

EntreDiversidades. Revista de Ciencias Sociales y Humanidades, vol. 8, núm. 1 (16), enero-junio 2021. Páginas: 258 - 276 ISSN-e: 2007-7610. https://doi.org/10.31644/ED.V8.N1.2021.D01 


\section{Bibliografía citada}

Alejos, José (1994). Mosojäntel etnografía del discurso agrarista entre los ch'oles de Chiapas. México: Instituto de Investigaciones Filológicas, Universidad Nacional Autónoma de México.

Bajtín, Mijaíl (1999). "El problema de los géneros discursivos”. Estética de la creación verbal. México: Siglo XXI, pp. 248-293.

Harman, Robert (1990 [1974]). Cambios médicos y sociales de una comunidad maya-tseltal. México: Instituto Nacional Indigenista/Consejo Nacional para la Cultura y las Artes.

Instituto Nacional de Estadística y Geografía (2020). Agenda Estadistica Chiapas 2010. [en línea] Ciudad, México: Comité Estatal de Información Estadística y Geográfica 2010.

Palomo, Dolores (2007). “'Enredos y sutilezas del derecho’. En defensa de los bienes comunes. La hacienda San Pedro Pedernal de Huixtán, Chiapas. 1790-1865". Revista Pueblos y fronteras, 2 (3), pp. 1-35. DOI: https://doi.org/10.22201/cimsur.18704115e.2007.3.231 (Consultado el 2 de abril de 2020). 